\title{
Performance assessment of residential mechanical exhaust ventilation systems dimensioned in accordance with Belgian, British, Dutch, French and ASHRAE standards.
}

\author{
J. Laverge ${ }^{1}$, X. Pattyn ${ }^{1} \&$ A. Janssens ${ }^{1}$ \\ ${ }^{1}$ Ghent University, Department of Architecture and Urban Planning, \\ Jozef Plateaustraat 22, Gent, Belgium \\ Corresponding Author: \\ tel +3292643749 / fax +3292644185 \\ email jelle.laverge@ugent.be
}

KEYWORDS: Exhaust ventilation; Residential ventilation; Pareto; Monte-Carlo; IAQ

\begin{abstract}
Sizing rules in residential ventilation standards lack uniformity in both methodology and resulting design flow rates. Additionally, mere comparison of design flow rates is case sensitive and, due to effects of infiltration, adventitious ventilation and occupancy, ill-suited to assess performance of an exhaust ventilation system with regard to the achieved indoor air quality and energy cost in terms of heat loss. This paper presents a multi-zone simulation based performance assessment of residential mechanical exhaust ventilation systems, using five common dwelling typologies and the sizing rules put forward in the Belgian, British, Dutch, French and ASHRAE residential ventilation standards. The performance of the different cases proved to be substantially different, with an occurrence of poor perceived air quality in 5\% or less of the occupation time for the Belgian, Dutch and French standard, and about 15\% for the British and ASHRAE standard. When the trade-off between indoor air quality and heat loss is considered, the cases with the Dutch and ASHRAE standard did not achieve pareto-optimal performance in comparison to the performances achieved by the other standards.
\end{abstract}

\section{INTRODUCTION}

The 1970's oil crisis caused the first wave of energy conservation campaigns in buildings. Improved airtightness of newly built dwellings and intensive weatherisation actions considerably reduced the amount of fresh air infiltration. As an unintended consequence of this, the incidence of indoor mould problems peaked and reports on high prevalence of occupants complaining of a wide variety of symptoms or physical discomfort, baptised 'sick building syndrome', emerged.

As a reaction to these problems with indoor air quality, ventilation standards were established in most western countries. Unfortunately, this did not happen on an internationally coordinated level, giving way to the introduction of a wide range of sizing rules. As there is no common methodology, like the one that was developed for non-residential buildings by CEN [1], that is used for the different standards, the flow rates proposed in them can't be compared easily. AIVC listed the requirements of 15 standards without attempting to analyse their performance [2]. A similar effort was done in the framework of the EPHECT project [3]. Two reviews, one by Yoshida [4] and another within the HEALTHVENT project [5] applied the sizing rules to a reference dwelling and found that the design air change rate in the majority of standards is around $0.5 \mathrm{ACH}$. 
In the moderate climate region of West-Europe, especially in Belgium, the Netherlands, France and the UK, simple exhaust mechanical ventilation systems dominate the residential ventilation market [6-8], while heat recovery ventilation and natural ventilation are the most common residential ventilation systems in northern and southern Europe respectively. Such simple exhaust systems are composed of a mechanical exhaust fan, ducted to a series of vent holes in the different 'wet' spaces in the dwelling such as kitchens, toilets, bathrooms and service rooms, combined with externally and internally mounted air transfer devices [9]. The externally mounted air transfer devices, also called trickle ventilators, are intentionally made perforations in the building shell that deliver the make-up air for the air extracted from the dwelling by the fan, while their internally mounted counterparts, also called transfer grilles, allow the air to flow from one space to an other. Since the introduction of ASHRAE 62.2, this kind of ventilation system is also rapidly achieving a dominant position in the US residential ventilation market, although the use of trickle ventilators is usually omitted and not treated as such in the standard. The sizing rules for the trickle ventilators in the standards of the 4 European countries also demonstrate little uniformity, requiring the design flow rate, which itself is different for all standards, to be achieved at a different design pressure difference across the ventilator, ranging between 1 and 20 $\mathrm{Pa}$.

The total air change rate achieved by simple exhaust ventilation systems can be considerably different from the flow rate of the fan due to adventitious ventilation and infiltration [10]. The importance of the extra flow rate is mainly related to the sizing of the trickle ventilators relative to the flow rate of the fan [11]. Therefore, the ventilation heat loss of exhaust ventilation systems can't be assessed comprehensively by simple comparison of the design flow rates. In addition, the air flow in the system is controlled by the mechanical flow rate only in the 'wet' spaces, whereas the flow rate in the rest of the dwelling, which comprises the main living spaces, is governed by much less stable driving forces such as wind and buoyancy. Since the occupants spent the vast majority of time in the livings spaces [12, 13], the indoor air quality (IAQ) achieved in these spaces will be the dominant contributor to perceived air quality [14]. Again, the design flow rates will not be a good metric for assessing the performance of simple mechanical exhaust ventilation systems.

In the EU, space heating accounts for about $26 \%$ of all final energy consumption $[15,16]$. Since energy performance criteria are being tightened and infiltration, adventitious and intended ventilation combined represent about $50 \%$ of the total heat loss in well insulated buildings, the 'right' flow rate and the corresponding sizing rules are at sixes and sevens. Keeping the problems that surfaced after the reductions in flow rate made during the 1970's energy crisis in mind, this debate should be based on a comprehensive analysis of the performance of the ventilation systems proposed in the standards.

Presenting the results from a multi zone simulation based performance assessment of simple mechanical ventilation systems sized in accordance with the Belgian [17], British [18], Dutch [19], French [20, 21], and ASHRAE [22] residential ventilation standards, this paper aims to contribute to this debate. The 4 european countries are chosen because of the dominance of exhaust ventilation in their ventilation market and their geographical clustering. Although exhaust ventilation historically also represents a large part of the residential ventilation market in 
the Nordic countries, their cold climate [10] and recent market evolutions favour heat recovery ventilation. Therefore they were not included. The ASHRAE standard was chosen for its large geographical applicability and it's authority in HVAC design. Additional motives include the fact that it's promotion of exhaust ventilation is novel in the US and it's recent publication. The sizing rules of each standard are applied to 5 common dwelling typologies and monte carlo analysis is used to consider the sensitivity of the results to the boundary conditions used.

\section{SIZING IN THE STANDARDS}

As was explained in the introduction, the sizing rules for simple exhaust residential ventilation systems put forward are different in the Belgian, Dutch, French, UK and ASHRAE standards. In this section, the specific rules found in each of the standards are summarized. If different sizing rules are provided for continuous and demand controlled systems, only those for continuous systems are considered.

\subsection{Belgium}

The Belgian standard requires a design flow rate of $11 / \mathrm{s}^{*} \mathrm{~m}^{2}$ for each occupied space. For the main living space, this design flow rate should be at least $21 \mathrm{l} / \mathrm{s}$ and can be limited to $42 \mathrm{l} / \mathrm{s}$, while for bedrooms, studies... the minimum value is $71 / \mathrm{s}$ and the design flow rate can be limited to $20 \mathrm{l} / \mathrm{s}$. For kitchens, bathrooms and service rooms, a minimum design flow rate of $14 \mathrm{l} / \mathrm{s}$ should be taken into account, while it can be limited to $21 \mathrm{l} / \mathrm{s}$. The design flow rate for a toilet is 7 1/s. Table 1. provides a summary of the design flow rates.

The occupied spaces and the wet spaces should be connected to each other or via circulation spaces by transfer grilles sized at $7 \mathrm{l} / \mathrm{s}$ at $2 \mathrm{~Pa}$ pressure difference, which corresponds to $70 \mathrm{~cm}^{2}$, except for the kitchen, in which the transfer grille should be sized twice as large. Each living space, bedroom, study... should be connected to the outdoor environment by a trickle ventilator sized at the design flow rate for that space at $2 \mathrm{~Pa}$ pressure difference.

\subsection{The Netherlands}

With a design flow rate of $0.91 / \mathrm{s}^{*} \mathrm{~m}^{2}$ for each occupied space and minimum design flow rates of $7 \mathrm{l} / \mathrm{s}$ in bedrooms, studies and toilets and $14 \mathrm{l} / \mathrm{s}$ in bathrooms and service rooms, the Dutch standard's sizing rules are quite similar to those in the Belgian standard. The minimum design flow rates for the kitchen, however, is set at $21 \mathrm{l} / \mathrm{s}$ instead of $14 \mathrm{l} / \mathrm{s}$, while in the main living space, only $7 \mathrm{l} / \mathrm{s}$ is required as opposed to $21 \mathrm{l} / \mathrm{s}$ in the Belgian standard. Furthermore, Trickle ventilators should be sized at the design flow rate at $1 \mathrm{~Pa}$ pressure difference and transfer grilles should have a free face area of $12 \mathrm{~cm}^{2}$ multiplied by the design flow rate for that space. As a consequence, the size of the trickle ventilators and transfer grilles is larger compared to the Belgian standard's sizing rules.

\subsection{France}

The design flow rate for each of the 'wet' spaces in the French standard depends on the number of 'main' spaces in the dwelling, eg. living spaces, bedrooms, studies.... These flow rates have been tabulated in table 2 . The design flow rates of the trickle ventilators in the remaining spaces are also defined as a function of the number of 'main' spaces. For dwellings with only 1 or 2 'main' spaces, the design flow rate is increased for higher total design flow rates in the 'wet' spaces (Table 3.) 
The trickle ventilators should be sized to the design flow rate at 20 Pa pressure difference, while the transfer grilles should be sized to the design flow rate at $5 \mathrm{~Pa}$ and $2.5 \mathrm{~Pa}$ for 'wet' and 'main' space grilles respectively. As a consequence, the size of components is typically smaller compared to the Dutch and Belgian standard's sizing rules.

\subsection{UK}

Simple exhaust ventilation is denominated 'extract ventilation' in the British standard. Design flow rates of 13, 8 and $61 / \mathrm{s}$ are required for kitchens, bathrooms and toilets respectively. Service rooms are treated as bathrooms. In addition to these design flow rates per space, the total extracted flow rate should not be less than $9 \mathrm{l} / \mathrm{s}$, increased with $4 \mathrm{l} / \mathrm{s}$ for each bedroom. The equivalent, referenced to a round sharp edged opening, free face area of transfer grilles is set at $76 \mathrm{~cm}^{2}$, that of the trickle ventilators at $25 \mathrm{~cm}^{2}$.

\subsection{ASHRAE}

The design flow rate for kitchens proposed in the ASHRAE standard is $5 \mathrm{ACH}$, while $10 \mathrm{l} / \mathrm{s}$ is required for bathrooms. The total design exhaust flow rate for a dwelling is at least $0.05 \mathrm{l} / \mathrm{s}^{*} \mathrm{~m}^{2}$, increased with $7 \mathrm{l} / \mathrm{s}$ for the first bedroom and $3.5 \mathrm{l} / \mathrm{s}$ for each additional bedroom. No requirements for trickle ventilators or transfer grilles are included.

\section{METHODS}

To assess the quality of the sizing rules in the standards discussed above, simple exhaust residential ventilation systems have been designed is accordance with the different standards for five different dwelling typologies. The geometries of the dwellings have been developed in the framework of a research project on the optimisation of building envelope and services for lowenergy residential buildings [23-25]. Their size and layout is based on an extensive survey of 200 dwellings in Belgium built in the 1990's [26] and have been used in several previous research projects eg. [27]. Their characteristics have been checked regularly with the evolution of newly built dwellings and still correspond well with current building practise. Four dwellings are single family houses, one is a flat. All dwellings have the same useful floor area corresponding to the mean from Belgian national statistical figures. All houses comprise a living room, 3 bedrooms, kitchen, bathroom, toilet, service room, and hall way, with a total net floor area of about $150 \mathrm{~m}^{2}$. The detached, semi-detached and terraced house hold a separate study. The dwellings differ in building compactness, ranging from a detached bungalow to a flat in a 6-floor apartment building. The market share of newly built dwellings during the last decade in Belgium is typically $40 \%$ detached houses, $40 \%$ flats and $20 \%$ terraced or semi-detached. In all countries studied, all types are typically found, with an overbalance of flats and terraced houses in the cities, whereas detached dwellings are dominantly found in rural areas. Table 4 gives an overview of geometrical characteristics of the five reference dwellings. The compactness is defined as the ratio of the volume to the heat loss area. Graphical representations of the floor plans are given in appendix to the paper.

The results presented in this paper are based on airflow simulations. These were executed in the multi-zone airflow simulation package Contam [28], which takes effects of buoyancy, wind and fan pressure into account and is used in numerous ventilation studies eg. [eg. 29, 30]. The validation of multi-zone ventilation models against e.g. tracer gas measurements is well 
documented in literature [31-34]. Multi-zone simulation models typically assume well mixed air in every room (simulated as a single node in the model). As a result, these models are not suited for detailed analysis of the distribution of contaminants in a single room. This aspect can be studied with computational fluid dynamics (CFD) [35-38]. However, this is not the scope of this papersincein contrast to a typical office setting, no specific occupied zone can be defined in a residential setting. In addition, CFD would be to computationally demanding for the scope of this paper. To assess the heat loss through hygiene ventilation, only the bulk fresh airflow in the building is relevant. As Contam is a ventilation model only, it cannot calculate transient room or duct temperatures. Therefore, for simplicity, the temperature inside the building and all ducts has been set to $18{ }^{\circ} \mathrm{C}$, the inside temperature fixed by the Belgian EPBD calculation procedure, which corresponds to the average temperature measured in Belgian dwellings [39]. The effect of this assumption has been discussed by Steeman [40, 41]. The test reference year for Ukkel, Belgium was used as the outdoor climate for all simulations, with hourly mean values for temperature, humidity, wind speed and direction.

\subsection{Building model}

The airflow in the dwellings has been modelled taking into account both the ventilation system and leakage. Overall leakage, characterized by the $v_{50}$ value, is modelled by means of cracks in the roof and wall surface. The $v_{50}$ value is the ratio of the air leakage rate at $50 \mathrm{~Pa}$ pressure difference and the building envelope heat loss area. According to observations by Bossaer [39], the specific leakage rate through roof and walls has a $2 / 3$ ratio, which has been implemented in the model. Each wall is fitted with two cracks, one at $1 / 4$ of its height and the second one at 3/4. The internal doors are simulated with additional cracks in the walls. For the indoor walls, a fixed specific leakage value is assumed. This methodology is in agreement with guidelines given in EN 15242 [42]. In the results presented, a specific airleakage $\left(\mathrm{v}_{50}\right)$ of $3 \mathrm{~m} / \mathrm{h}$ is used, representing the best quartile of measured airtightness values in a measurement campaign in Flanders in the late 90's [39]. A recent measurement campaign [43], along with results from other countries [44], shows a tendency towards this level of airtightness in newly built dwellings.

The production of $\mathrm{CO}_{2}$ within the model is only related to the occupants' metabolism and corresponds to their whereabouts. A constant outdoor background concentration of $350 \mathrm{ppm}$ is assumed.

\subsection{Ventilation system design and model}

The design exhaust flow rate for the wet spaces in the dwellings according to the different standards are listed in Table 5. Since the design exhaust flow rates in most standards are size independent, the flow rates are mostly the same for all 5 dwellings. If this is not the case, the range of the design flow rates for that space in the 5 dwellings is mentioned. Since trickle ventilators are sized with respect to different reference pressure differences in the five standards, the flow coefficient at $1 \mathrm{~Pa}$ pressure difference, assuming a flow exponent of 0.5 and a simple power law flow profile, for the trickle ventilators in the various living spaces of the dwellings according to the different standards are listed in Table 6. Note that the ASHRAE standard does not require the installation of trickle ventilators.

All mechanical exhaust vents were modelled as constant volume flow rate components in the respective zone node, while transfer grilles and trickle ventilators were modelled with single direction power law flow components with a flow exponent of 0.5 [45]. All systems were 
modelled with windows and internal doors closed, in order to simulate the performance of the systems as such, without user interaction.

\subsection{Assessment parameters}

Through the correlation between excess $\mathrm{CO}_{2}$ concentration and mean percentage of dissatisfied [46] and Fanger's Perceived Air Quality approach [14], excess $\mathrm{CO}_{2}$ concentration is now widely accepted as a proxy for perceived indoor air quality [1], especially if the main pollution sources are related to the human metabolism. In contrast to the basic model, steady state conditions are rarely applicable to real ventilated environments. $\mathrm{CO}_{2}$ concentrations are inherently transient, due to changes in environmental boundary conditions. Additionally, the relevant $\mathrm{CO}_{2}$ sources tend to constantly move around in the multi-spaced dwelling, introducing discontinuous sources and further increasing the transient character of the indoor air quality. There is no consensus in literature about the way transient concentrations have to be interpreted. This lack of agreement is reflected in the disparate list of performance criteria provided in EN 15665 [47]. From the suggested parameters in this standard, 4 were selected for use in this paper, namely the heating season average $\mathrm{CO}_{2}$ concentration to which an occupant is exposed, the amount of time an occupant spends in an environment within the different IDA classes [1] and the dose of $\mathrm{CO}_{2}$ over $1000 \mathrm{ppm}$ excess $\mathrm{CO}_{2}$. The latter is expressed normalised to both the total time of the heating season and to the time in excess of $1000 \mathrm{ppm}$. The best IDA class, IDA 1, corresponds to exposure lower than $400 \mathrm{ppm}$ excess $\mathrm{CO}_{2}$, while the lowest class, IDA 4, exposure to concentrations in excess of 1000 excess $\mathrm{CO}_{2}$, is considered to correspond to poor perceived indoor air quality. Further, a comfort zone between $30-70 \%$ relative humidity is considered.

Exposure to emissions originating from building materials and their secondary effects can be reduced effectively with source control measures [48, 49]. Therefore, it is not considered as a performance indicator for the ventilation systems in this paper. Likewise, exposure to emissions due to specific activities such as cooking[50-54], cleaning[55-58], indoor smoking [59-62] is not considered since it is best controlled by either source control or intensive local ventilation.

The total, heating season averaged, convective heat loss through the combination of intended ventilation, adventitious ventilation and infiltration is used to assess the energy performance of the different sizing rules. Fan power was not taken into account because it is very system specific.Since heat loss and exposure reduction are opposing interests, they have to be trade off against each other $[63,64]$. Several authors have proposed using weighted sums of these different criteria $[65,66]$. The definition of these weighting coefficients, however, lacks scientific evidence. Therefore, the trade-off is addressed by means of the concept of pareto optimality. Pareto optimal cases are cases where none of the other standards achieve better results on both indoor air quality and heat loss.

\subsection{Sensitivity}

One of the main problems with simulation models is the uncertainty on input data, despite the fact that the sensitivity of the results to variation in the input data may be very high. A lot of variables have a distinct influence on the performance of the system and consequently the performance of the system will be different for each set of parameters. Therefore, the use of a calculation method that takes both the variation of the different parameters as well as the interaction between them into account is required to acquire statistically relevant data. Large sensitivity to input uncertainty often appears near equilibrium situations $[67,68]$ which occur for specific values of structural parameters or weather conditions [11]. 
To prevent this input dependency of the results, the Monte-Carlo (MC) approach, as proposed by Van Den Bossche et al. [69, 70], has been used in this study. In this approach, instead of fixing 1 value for each input data, a distribution is determined for the key parameters and multiple simulations are carried out with different values of these parameters. According to Furbringer $[67,68]$ convergence can be reached within 100 simulations if the amount of input parameters is limited.

Sensitivity analysis based on a Monte Carlo algorithm has been implemented in building simulation by e.g. Breesch [71]. Dorer et al. [72, 73] presented work specifically for residential ventilation systems within the framework of the EC Reshyvent - EU cluster project.

The Monte-Carlo process can be speeded up by using Low Discrepancy Sequences (LDS) instead of random numbers [74]. In contrast to randomly sampled points, they distribute the instances to empty areas in the sample space to prevent overlapping and clusters, which are very common with ordinary random numbers. Another advantage of LDS is that these sequences are entirely repeatable, giving the same sequence every time. These sequences are used to generate the parameter sets used in this paper.

A sensivity analysis has pointed out that wind related factors such as wind velocity and wind reduction parameters [75] and the number of inhabitants and their occupancy schedules have the biggest influence on the overall performance of the ventilation system [69]. Since wind conditions can change considerably due to the specific site and the territory of several standards includes multiple climate zones, the sensitivity to wind is taken into account by considering a distribution on the wind exposure parameters rather than changing the climate data.

The following input variables are considered with a probabilistic approach (Normal distributions are mentioned as $\mathrm{N}($ mean, standard deviation):

- Façade orientation - interval $\left[0^{\circ} ; 359^{\circ}\right]$

- $\quad \mathrm{C}_{\mathrm{p}}$ coefficients - interval of the 6 AIVC tables [76]

- Terrain roughness $\alpha$, partially correlated with the $C_{p}$ coefficients - interval [0.1490.377]

- $\quad$ Sunday is the ... ${ }^{\text {th }}$ day of the year - interval $[1 ; 7]$

- Moisture production from domestic activities - normal distribution (see below)

- Production of moisture and carbon dioxide by occupants - normal distribution (see below)

- Number of occupants - specific distribution

- Weekday / weekend occupancy schedules - specific distribution

The number of parameters can be considered to be small, so 100 datasets will be used to perform the simulations. Moisture production for domestic activities is based on data available in the EU technical report on design and dimensioning of residential ventilation systems [77]. The production in the bathroom is $\mathrm{N}(0.5,0.05) \mathrm{l} / \mathrm{s}$, in the service room cloth drying is $\mathrm{N}(1,0.05) 1 / \mathrm{s}$ and for cooking, a half hour cycle of $\mathrm{N}(0.6,0.05) \mathrm{l} / \mathrm{s}, \mathrm{N}(1,0.1) \mathrm{l} / \mathrm{s}$ and $\mathrm{N}(1.5,0.1) \mathrm{l} / \mathrm{s}$ for 10 minutes each is used. The production of moisture and carbon dioxide by occupants is modelled as a linear function of the metabolism, which varies for each activity (eg. $\mathrm{N}(0.8,0.05)$ Met for sleeping, $\mathrm{N}(2,0.1)$ Met for cooking). Based on EN 15251[78], the production rate is 11.875 1/h/Met for $\mathrm{CO}_{2}$ and $34.375 \mathrm{~g} / \mathrm{h} / \mathrm{Met}$ for moisture. The number of occupants and the occupancy schedules are considered with a specific distribution based on the social demography and time use studies in Belgium. Based on the available data, 100 different data sets were compiled with different occupancy schedules. The number of occupants in the building varies from one to six (1: $3 \%, 2: 21 \%, 3: 31 \%, 4: 32 \%, 5: 10 \%, 6: 3 \%)$, with an average of 3.34 persons per building.

\section{RESULTS AND DISCUSSION}


As was mentioned in the methods section, the indoor air quality provided by the sizing rules found in the Belgian, British, Dutch, French and ASHRAE standards is assessed using 4 different criteria for $\mathrm{CO}_{2}$ concentrations suggested by the EN 15665 standard [47]. All of these, however, integrate the transient concentrations into a single number, losing lots of information in the process. Therefore, the cumulative distribution functions of the exposure to $\mathrm{CO}_{2}$ are also given for some configurations. In figure 1, the 4 criteria are shown in the cumulative distribution chart.

Table 7 lists the time fractions spent in the different IDA classes considering all 334 occupants from the 100 simulations in the monte-carlo analysis for all 5 standards in all 5 geometries.

Looking at the cumulative distribution of the excess carbon dioxide concentration for the bungalow (Figure 2) and the flat (Figure 3), a few typical results can be deduced. The Belgian, Dutch and French standard consistently achieve similar indoor air quality, at a level that is considerably higher than that achieved by the British standard. The performance of the systems sized according to the ASHRAE standard, relative to the other standards, is much more prone to variation due to the fact that the flow rate is mainly concentrated in the kitchen and expressed as a function of its volume. Although the flow rates are similar in magnitude to those prescribed in the French standard, the lack of transfer grilles in the ASHRAE standard prevents a good distribution of this flow rate through the rest of the dwelling. Position and size of the kitchen relative to the other spaces therefore has a large influence on the achieved performance.

This is also reflected in the average excess carbon dioxide concentration to which the occupants are exposed, as well as in the dose above 1000 ppm excess carbon dioxide, both normalized to the total time of the simulation and to the time above that concentration. These criteria are listed in Table 8, along with the heating season averaged specific convective heat loss of the dwellings considered. Although general trends are similar for all criteria, the ranking of the different standards sometimes flips completely from one criterion to the next. The Belgian standard, in the terraced house, for instance, is ranked first if average exposure to excess carbon dioxide concentration is the criterion, second if the dose over $1000 \mathrm{ppm}$ of excess carbon dioxide normalized to the total time and the fraction of time in IDA 4 (carbon dioxide concentration higher that $1000 \mathrm{ppm}$ ) is considered and fourth measured by the dose over $1000 \mathrm{ppm}$ normalized to the time in IDA 4.

Figure 4 shows the cumulative distribution of the air change rate in the semi-detached dwelling. The median as well as first and third quartile values for all dwellings and all standards are listed in table 9. A clear distinction is seen between the Belgian and Dutch standard on the one hand and the British, French and ASHRAE standard on the other. The air change rate in the latter group is much less susceptible to variation due to changing boundary conditions due to the smaller sizing of trickle ventilators or the absence thereof compared to the Belgian and Dutch standard that require relatively large trickle ventilators. The Belgian, Dutch, French and ASHRAE standard all achieve median air change rates close to $0.5 \mathrm{ACH}$, that, as was mentioned in the introduction, can be considered a consensus value for residential buildings, while the system sized according to the British standard consistently renders about $40 \%$ lower values. 
Relative humidity was within the acceptable range within the vast majority of time $(80 \%)$ in almost all spaces in all dwellings and for all standards. As is shown in figure 5, although moisture producing activities are concentrated in the 'wet' spaces, the highest frequency of excessive relative humidity is found in the living room and bedrooms. This is readily explained by the fact that exhaust systems mechanically assure a constant exhaust flow rate from these wet spaces.

Figures 6 and 7 show the cumulative distribution of the ventilation heat loss for both the detached and the semi-detached house for all 5 standards, taking into account both intended and adventitious ventilation as well as infiltration. The same conclusions as with the air change rate apply.

If the trade-off between heat loss and indoor air quality is considered (Figure 8), using the average ventilation heat loss for the former and the average carbon dioxide to which the occupants are exposed as the criterion for the latter, the French and British standard provide pareto optimal solutions for each dwelling, although the fact that the indoor air quality achieved by the British standard is to be considered 'poor' $15 \%$ of the time is a cause of concern. Compared to the French standard, for example, the exposure to carbon dioxide of the cases using the ASHRAE standard is on average $40 \%$ higher, with higher or comparable heat losses (+16 to $8 \%$ ). Similarly, the ventilation heat loss in 4 cases using the Dutch standard is on average $20 \%$ higher than that in the cases with the French standard for higher or comparable carbon dioxide exposure $(+10$ to $-5 \%)$. In the flat, the heat losses using the French standard were comparable to those using the Dutch standard $(+4 \%)$ with lower exposure to carbon dioxide $(-26 \%)$.

\section{CONCLUSION}

Sizing rules in residential ventilation standards lack uniformity in both methodology and resulting design flow rates. Mere comparison of design flow rates is case sensitive and, due to effects of infiltration, adventitious ventilation and occupancy, ill-suited to assess performance of an exhaust ventilation system with regard to the achieved indoor air quality and energy cost in terms of heat loss. A performance assessment of residential mechanical exhaust ventilation systems using five common dwelling typologies and the sizing rules put forward in the Belgian, British, Dutch, French and ASHRAE residential ventilation standards in multi-zone simulations with Monte-carlo based sensitivity analysis presented above showed that the performance of the different cases proved to be substantially different. An occurrence of poor perceived air quality in 5\% or less of the occupation time for the Belgian, Dutch and French standard, and about 15\% for the British and ASHRAE standard was found.

Except for the cases with the ASHRAE standard, the relative performance of the standards was consistent throughout the different building typologies. The spread observed in the performance of the cases using the ASHRAE standard can be attributed to the larger impact of geometrical parameters on the system design in this standard. In some cases, the relative performance of the standards was sensitive to the indoor air quality criterion used in the assessment, although the general trends could be observed with each of the criteria.

The total air change rate was close to or greater than the consensus value of $0.5 \mathrm{ACH}$ in most cases, except in the cases using the British standard, where it was consistently about $40 \%$ lower. The cases using the Belgian and Dutch standards, with relatively large trickle ventilators, 
rendered the air change rates most sensitive to changes in boundary conditions. When the tradeoff between indoor air quality and heat loss is considered, the cases with the Dutch and ASHRAE standard did not achieve pareto-optimal performance.

Considering the performance spread observed, harmonization of residential ventilation standards is to be recommended. The design philosophy of the French standard proves to be a good basis for exhaust ventilation design with high occurrence of good perceived air quality, minimized ventilation heat loss and robust performance. It's combination of moderately high exhaust flow rates, large transfer devices and small trickle ventilators should explored further when new, more uniform standards are developed.

\section{APPENDIX}

Figures 9-13 show the floor plans of the 5 reference dwellings. In each figure, the different spaces are numbered as follows: livingroom (1), kitchen (2), toilet (3), bathroom (4), bedrooms (5-7), study (8), service room (9), hall (10).

[1] CEN, Ventilation for non-residential builidings - performance requirements for ventilation and room-conditioning systems, in, Brussels, 2007.

[2] M.J. Limb, A Review of International Ventilation, Airtightness, Thermal Insulation and Indoor Air Quality Criteria, in: AIVC Technical Notes, AIVC, 2001, pp. 203.

[3] C. Dimitroulopoulou, Ventilation in European dwellings: A review, Building and Environment, 47 (0) (2012) 109-125.

[4] H. Yoshino, S. Murakami, S.-i. Akabayashi, T. Kurabuchi, S. Kato, S.-i. Tanabe, K. Ikeda, H. Osawa, T. Sawachi, A. Hukushima, M. Adachi, Survey on minimum ventilation rate of residential buildings in fifteen countries, in: AIVC, Prague, 2004.

[5] N. Brelih, O. Seppänen, Ventilation rates and IAQ in european standards and national regulations, in: AIVC conference, Brussels, 2011.

[6] F. Durier, Trends in the French building ventilation market and drivers for changes, in: AIVC (Ed.) Ventilation Information Papers, 2008.

[7] W. De Gids, Ventilation in Dutch houses - a study in a representative sample of the dutch housing stock, in: 24th AIVC conference: ventilation, humidity control \& energy, AIVC, Washington DC, 2003.

[8] K. Clarys, EPB: analyse van Vlaamse woningen en

overheidsmaatregelen op energetisch vlak, Architecture and Urban Planning, Ghent University, 2012.

[9] CEN, Ventilation for buildings - Performance testing of components/products for residential ventilation - part. 1: extarnally and internally mounted air transfer devices, in, Brussels, 2004.

[10] J. Laverge, A. Janssens, Heat recovery ventilation operation traded off against natural and simple exhaust ventilation in Europe by primary energy factor, carbon dioxide emission, household consumer price and exergy, Energy and Buildings, 50 (0) (2012) 315-323.

[11] J. Laverge, Comparison of the use of trickle ventilators in european residential ventilation standards, in: Roomvent 2011, Trondheim, 2011.

[12] M. Basner, K.M. Fomberstein, F.M. Razavi, S. Banks, J.H. William, R.R. Rosa, D.F. Dinges, American time use survey: Sleep time and its relationship to waking activities, Sleep, 30 (9) (2007) 1085-1095.

[13] I.M. Glorieux, J., Belgisch tijdsbudgetonderzoek, in, Brussels, 2008. 
[14] P.O. Fanger, Introduction of the olf and decipol unit to quantify air-pollution perceived by humans indoors and outdoors, Energy and Buildings, 12 (1) (1988) 1-6.

[15] J. Bosh, F.X. Johnson, R. Mertens, N. Roubanis, P. Loesoenen, A. Gikas, J. Gorton, Panorama of Energy: Energy statistics to support EU politics and solutions, 2007.

[16] IEA, Energy Balances of OECD Countries 2008, 2008.

[17] BIN, Ventilatievoorzieningen in woongebouwen, in, Brussels, 1991.

[18] Building regulations 2000: approved document F - means of ventilation, in: O.f.t.D.P. Minister (Ed.), 2006.

[19] NNI, Ventilatie van gebouwen - Bepalingsmethoden voor nieuwbouw, in, Delft, 2006.

[20] Arrêté du 24 mars 1982 relatif à l' aération des logements, modifié par Arrêté du 28 ocotobre 1983, in, journal officiel de la république française du 15 novembre 1983, 1983.

[21] Installations de ventilation mécanique contrôlée - Règles de conception

et de dimensionnement, in: XP P50-410 (DTU 68.1), 1995.

[22] Ashrae, Ventilation and Acceptable Indoor Quality in Low-Rise Residential

Buildings, in, Atlanta, GA, 2010.

[23] G. Verbeeck, Life cycle optimization of extremely low energy dwellings, J. Build Phys., 31

(2) (2007) 143-177.

[24] G. Verbeeck, H. Hens, Life cycle inventory of buildings: A calculation method, Building and Environment, 45 (4) 1037-1041.

[25] G. Verbeeck, H. Hens, Life cycle inventory of buildings: A contribution analysis, Building and Environment, 45 (4) 964-967.

[26] WTCB, WENK, VLIET, SENVIVV: Studie van de Energieaspecten van Nieuwbouwwoningen in Vlaanderen: Isolatie, Ventilatie, Verwarming, in, (in dutch), Brussels, 1998.

[27] A. Janssens, L. Willems, J. Laverge, Performance evaluation of residential ventilation systems based on multi-zone ventilation models, in: N.T. Bayazit, G. Manioglu, G.K. Oral, Z. Yilmaz (Eds.) Proceedings of 4th international building physics conference, Istanbul Technical University, 2009, pp. 833-839.

[28] W.S. Dols, A tool for modeling airflow \& contaminant transport, Ashrae Journal, 43 (3) (2001) 35-+.

[29] G. Nirvan, F. Haghighat, L. Wang, H. Akbari, Contaminant transport through the garage House interface leakage, Building and Environment, 56 (0) (2012) 176-183.

[30] Y.L. Chen, J. Wen, The selection of the most appropriate airflow model for designing indoor air sensor systems, Building and Environment, 50 (0) (2012) 34-43.

[31] S.J. Emmerich, Validation of multizone IAQ modeling of residential-scale buildings: a review, in: ASHRAE Transactions, ASHRAE, Cincinnati, 2001, pp. 619-628.

[32] S.J. Emmerich, Validation of contamw predictions for tracer gas in a townhouse, in: IBPSA (Ed.) 8th international IBPSA conference, IBPSA, Eindhoven, 2003, pp. 299-306.

[33] A. Delsante, S. Aggerholm, The use of simulation tools to evaluate hybrid ventilation control strategies, in: Annex 35 technical report, IEA/ECBCS, 2002.

[34] A. Bossaer, D. Ducarme, P. Wouters, L. Vandaele, An example of model evaluation by experimental comparison: pollutant spread in an apartment, Energy and Buildings, 30 (1) (1999) 53-59.

[35] L.J. Lo, A. Novoselac, Cross ventilation with small openings: Measurements in a multi-zone test building, Building and Environment, 57 (0) (2012) 377-386. 
[36] Z.A. Adamu, A.D.F. Price, M.J. Cook, Performance evaluation of natural ventilation strategies for hospital wards - A case study of Great Ormond Street Hospital, Building and Environment, 56 (0) (2012) 211-222.

[37] R. Ramponi, B. Blocken, CFD simulation of cross-ventilation for a generic isolated building: Impact of computational parameters, Building and Environment, 53 (0) (2012) 34-48.

[38] N. Nikolopoulos, A. Nikolopoulos, T.S. Larsen, K.-S.P. Nikas, Experimental and numerical investigation of the tracer gas methodology in the case of a naturally cross-ventilated building, Building and Environment, 56 (0) (2012) 379-388.

[39] A. Bossaer, J. Demeester, P. Wouters, B. Vandermarke, W. Vangroenweghe, Airtightness performances in new Belgian dwellings, in: 19th AIVC conference: ventilation technologies in urban areas, AIVC, Oslo, 1998, pp. 77-84.

[40] M. Steeman, J. Laverge, On modelling moisture buffering when evaluating humidity controlled hvac systems, in: Building Simulation 2009, Glasgow, 2009, pp. 819-826.

[41] M. Steeman, A. Janssens, H.J. Steeman, M. Van Belleghem, M. De Paepe, On coupling 1D non-isothermal heat and mass transfer in porous materials with a multizone building energy simulation model, Building and Environment, 45 (4) 865-877.

[42] CEN, Ventilation for buildings - Calculation methods for the determination of air flow rates in buildings including infiltration, in, Brussels, 2007.

[43] J. Laverge, S. Vandevelde, T. Debrauwere, M. Delghust, A. Janssens, Airtightness assessment of newly build single family houses in Belgium, in: Buildair 2010, Copenhagen, 2010.

[44] W. Pan, Relationships between air-tightness and its influencing factors of post-2006 newbuild dwellings in the UK, Building and Environment, 45 (11) 2387-2399.

[45] P. Karava, T. Stathopoulos, A.K. Athienitis, Investigation of the performance of trickle ventilators, Building and Environment, 38 (8) (2003) 981-993.

[46] CEN, Ventilation for buildings - Design criteria for the indoor environment, in, Brussels, 1998.

[47] CEN, Ventilation in buildings - Determining performance criteria for design of residential ventlilation systems, in, Brussels, 2009.

[48] H.N. Knudsen, P. Wargocki, Strategy for good perceived air quality in sustainable buildings, in: Clima 2010, Antalya, 2010.

[49] J. Kurnitski, O.A. Seppanen, Trends and drivers in the Finnisch ventilation and AC market, in: AIVC (Ed.) Ventilation Information Papers, AIVC, Brussels, 2008.

[50] J. Baumgartner, J.J. Schauer, M. Ezzati, L. Lu, C. Cheng, J. Patz, L.E. Bautista, Patterns and predictors of personal exposure to indoor air pollution from biomass combustion among women and children in rural China, Indoor Air, 21 (6) (2011) 479-488.

[51] M.-P. Wan, C.-L. Wu, G.-N.S. To, T.-C. Chan, C.Y.H. Chao, Ultrafine particles, and $\operatorname{PM}(2.5)$ generated from cooking in homes, Atmospheric Environment, 45 (34) (2011) 61416148.

[52] E. Kabir, K.-H. Kim, An investigation on hazardous and odorous pollutant emission during cooking activities, Journal of Hazardous Materials, 188 (1-3) (2011) 443-454.

[53] G. Buonanno, L. Morawska, L. Stabile, Particle emission factors during cooking activities, Atmospheric Environment, 43 (20) (2009) 3235-3242.

[54] S.W. See, R. Balasubramanian, Chemical characteristics of fine particles emitted from different gas cooking methods, Atmospheric Environment, 42 (39) (2008) 8852-8862. 
[55] Y. Huang, K.F. Ho, S.S.H. Ho, S.C. Lee, P.S. Yau, Y. Cheng, Physical parameters effect on ozone-initiated formation of indoor secondary organic aerosols with emissions from cleaning products, Journal of Hazardous Materials, 192 (3) (2011) 1787-1794.

[56] A.C. Steinemann, I.C. MacGregor, S.M. Gordon, L.G. Gallagher, A.L. Davis, D.S. Ribeiro, L.A. Wallace, Fragranced consumer products: Chemicals emitted, ingredients unlisted, Environmental Impact Assessment Review, 31 (3) (2011) 328-333.

[57] B.K. Coleman, M.M. Lunden, H. Destaillats, W.W. Nazaroff, Secondary organic aerosol from ozone-initiated reactions with terpene-rich household products, Atmospheric Environment, 42 (35) (2008) 8234-8245.

[58] K.-D. Kwon, W.-K. Jo, H.-J. Lim, W.-S. Jeong, Volatile pollutants emitted from selected liquid household products, Environmental Science and Pollution Research, 15 (6) (2008) 521526.

[59] A.M. Butz, P. Breysse, C. Rand, J. Curtin-Brosnan, P. Eggleston, G.B. Diette, D.A. Williams, J.T. Bernert, E.C. Matsui, Household Smoking Behavior: Effects on Indoor Air Quality and Health of Urban Children with Asthma, Maternal and Child Health Journal, 15 (4) (2011) 460-468.

[60] F. Gleich, U. Mons, M. Poetschke-Langer, Air Contamination Due to Smoking in German Restaurants, Bars, and Other Venues-Before and After the Implementation of a Partial Smoking Ban, Nicotine \& Tobacco Research, 13 (11) (2011) 1155-1160.

[61] J.M. Lim, J.H. Jeong, J.H. Lee, J.H. Moon, Y.S. Chung, K.H. Kim, The analysis of PM2.5 and associated elements and their indoor/outdoor pollution status in an urban area, Indoor Air, 21 (2) (2011) 145-155.

[62] L.M. Petrick, M. Sleiman, Y. Dubowski, L.A. Gundel, H. Destaillats, Tobacco smoke aging in the presence of ozone: A room-sized chamber study, Atmospheric Environment, 45 (28) (2011) 4959-4965.

[63] J. Laverge, A. Janssens, Residential ventilation system optimization using monte-carlo and genetic algorithm techniques, in: IAQ 2010, ASHRAE, Kuala Lumpur, 2010, pp. 10.

[64] R. Becker, I. Goldberger, M. Paciuk, Improving energy performance of school buildings while ensuring indoor air quality ventilation, Building and Environment, 42 (9) (2007) 32613276.

[65] M. Ncube, S. Riffat, Developing an indoor environment quality tool for assessment of mechanically ventilated office buildings in the UK - A preliminary study, Building and Environment, 53 (0) (2012) 26-33.

[66] D. Johansson, The life cycle costs of indoor climate systems in dwellings and offices taking into account system choice, airflow rate, health and productivity, Building and Environment, 44 (2) (2009) 368-376.

[67] J.M. Furbringer, C.A. Roulet, Confidence of simulation results: put a sensitivity analysis module in your MODEL - The IEA-ECBCS Annex 23 experience of model evaluation, Energy and Buildings, 30 (1) (1999) 61-71.

[68] J.M. Furbringer, C.A. Roulet, Comparison and combination of factorial and Monte-Carlo design in sensitivity analysis, Building and Environment, 30 (4) (1995) 505-519.

[69] N. Van Den Bossche, A. Janssens, N. Heijmans, P. Wouters, Performance evaluation of humidity controlled ventilation strategies in residential buildings, in: Thermal performance of the exterior envelopes of whole buildings X, Clearwater, 2007, pp. 7. 
[70] J. Laverge, N. Van den Bossche, N. Heijmans, A. Janssens, Energy saving potential and repercussions on indoor air quality of demand controlled residential ventilation strategies, Building and Environment, 46 (7) (2011) 1497-1503.

[71] H. Breesch, A. Janssens, Performance evaluation of passive cooling in office buildings based on uncertainty and sensitivity analysis, Sol. Energy, 84 (8) (2010) 1453-1467.

[72] V. Dorer, A. Pfeiffer, A. Weber, Parameters for the design of demand controlled hybrid ventilation systems for residential buildings, in: AIVC Technical Notes, AIVC, Brussels, 2005, pp. 120.

[73] A. Pfeiffer, V. Dorer, A. Weber, Modelling of cowl performance in building simulation tools using experimental data and computational fluid dynamics, Building and Environment, 43 (8) (2008) 1361-1372.

[74] M. Winiarski, Quasi-Monte Carlo dervative valuation and reduction of simulation bias, Royal Institute of Technology, 2003.

[75] D. Costola, B. Blocken, J.L.M. Hensen, Overview of pressure coefficient data in building energy simulation and airflow network programs, Building and Environment, 44 (10) (2009) 2027-2036.

[76] M.W. Liddament, A guide to energy efficient ventilation, in: AIVC Guides, AIVC, Brussels, 1996.

[77] CEN, Ventilation for buildings - Design and dimensioning of residential ventilation systems, in, Brussels, 2005.

[78] CEN, Criteria for the indoor environment, inluding thermal, indor air quality, light and noise, in, Brussels, 2005. 
Figure captions:

Figure 1. Cumulative distribution of the $\mathrm{CO} 2$ concentration to which the occupants are exposed for the flat case under the sizing rules of the British standard, with marks indicating the average concentration $(\Delta)$, the dose above 1000 ppm normalized to the total time $(\boldsymbol{\square})$ and to the time above 1000 ppm (X). Limits between IDA classes are indicated by vertical lines.

Figure 2. Cumulative distribution of the $\mathrm{CO} 2$ concentration to which the occupants are exposed for the bungalow case (b) under the sizing rules of the Belgian (B), French $(F)$, Dutch $(N)$, British (U) and ASHRAE (A) standard.

Figure 3. Cumulative distribution of the $\mathrm{CO} 2$ concentration to which the occupants are exposed for the flat case (a) under the sizing rules of the Belgian (B), French (F), Dutch (N), British (N) and ASHRAE (A) standard.

Figure 4. Cumulative distribution of the air change rate in the Semi-Detached dwelling for all 5 standards.

Figure 5. Relative humidity in all spaces of the Terraced dwelling for all 5 standards (Living Room - LR, Study - ST, Bedroom 1-3 - B1-3, Kitchen - KT, Service Room - SR, Toilet - TL, Bathroom - BR)

Figure 6. Cumulative distribution of ventilation heat loss in the detached dwelling for all 5 standards.

Figure 7. Cumulative distribution of ventilation heat loss in the terraced dwelling for all 5 standards.

Figure 8. Heating season averaged ventilation heat loss traded-off against average carbon dioxide concentration to which occupants are exposed during the heating season for all 5 standards in all 5 dwellings (flat - black solid fill, terraced - grey line, semi-detached - dark grey solid fill, detached - light grey solid fill, bungalow - black line, symbols correspond to the standards, as shown in the legend.)

Figure 9. Floorplan of the bungalow.

Figure 10. Floorplan of the detached house.

Figure 11. Floorplan of the semi-detached house.

Figure 12. Floorplan of the terraced house.

Figure 13. Floorplan of the flat. 